\title{
Occurrence of Subclinical Atrial Fibrillation in the Follow-up of Patients with Cardiac Pacemakers
}

\section{Ocorrência de Fibrilação Atrial Subclínica no Acompanhamento de Pacientes Portadores de Marcapasso Cardíaco}

Luis Fernando Spagnuolo Brunello ${ }^{1, *}$, Gustavo Andrade de Figueiredo ${ }^{1}$, Leonardo Andrade Mulinari ${ }^{1}$

\author{
ORCID IDS \\ Brunello LFS (D) https://orcid.org/0000-0001-7717-5835 \\ Figueiredo GA (D) https://orcid.org/0000-0003-1907-1637 \\ Mulinari LA (D) https://orcid.org/0000-0001-7138-9912
}

\begin{abstract}
Objective: Cardiac pacemaker records atrial fibrillation (AF). This condition can cause serious hemodynamic consequences to patients, who should be assisted by a cardiologist. This study aimed to document and investigate, in a tertiary hospital, the prevalence of subclinical AF in patients with a cardiac pacemaker. Methods: Between July 2015 and April 2016, 196 patients with pacemakers were attended on an outpatient basis. Of these, 60 had cardiac arrhythmias recorded by the pacemaker and were invited to participate in the study. Data collection was done through a structured interview containing four questions: gender, age, follow-up with cardiologist and use of anticoagulants. Results: Subclinical AF was recorded in 35 (17.8\%) of the total of 196 patients. Of these 35, 16 (45.7\%) did not follow a regular cardiology service and 29 (82.8\%) did not use anticoagulant medication. No statistically significant relationships were found between age, follow up with a cardiologist, and presence or absence of subclinical AF in the patients studied. Conclusion: A significant portion of outpatient patients with pacemakers have AF recorded by the device. However, although essential, almost half of these do not proceed with the clinical follow-up with cardiologist and less than a fifth with AF makes use of anticoagulant therapy.
\end{abstract}

KEYWORDS: Artificial pacemaker; Atrial fibrillation; Cardiac arrhythmias; Hospital outpatient clinic

\section{RESUMO}

Objetivo: O marcapasso cardíaco registra a fibrilação atrial (FA). Essa condição pode causar graves consequências hemodinâmicas aos pacientes, que devem ser assistidos por médico cardiologista. Este estudo objetivou documentar e investigar, em um hospital terciário, a prevalência de FA subclínica em portadores de marcapasso cardíaco. Métodos: Entre julho de 2015 e abril de 2016, foram atendidos 196 pacientes portadores de marca-passo em caráter ambulatorial. Desses, 60 apresentaram arritmias cardíacas registradas pelo marcapasso e foram convidados a participar do estudo. A coleta de dados foi feita por meio de entrevista estruturada contendo quatro questões: sexo, idade, acompanhamento com cardiologista e uso de anticoagulantes. Resultados: Foi registrada FA subclínica em 35 $(17,8 \%)$ do total de 196 pacientes. Desses 35, $16(45,7 \%)$ não realizavam acompanhamento regular em serviço de cardiologia e 29 (82,8\%) não faziam uso de medicamento anticoagulante. Não foram encontradas relações estatisticamente significativas entre idade, acompanhamento com cardiologista e presença ou ausência da FA subclínica nos pacientes estudados. Conclusão: Uma parcela significativa dos pacientes portadores de marcapasso atendidos ambulatorialmente tem FA registrada pelo dispositivo. No entanto, ainda que essencial, quase metade desses não faz acompanhamento clínico com cardiologista e menos de um quinto com FA faz uso de terapia anticoagulante.

PALAVRAS-CHAVE: Marcapasso artificial; Fibrilação atrial; Arritmias cardíacas; Ambulatório hospitalar

1. Universidade Federal do Paraná - Hospital de Clínicas - Serviço de Cirurgia Cardiovascular - Curitiba/PR - Brazil.

*Correspondence author: luisbrunello@gmail.com

Received: 09 Oct 2018 | Accepted: 06 May 2019

Section Editor: J. Tarcísio Medeiros de Vasconcelos 


\section{INTRODUCTION}

Atrial fibrillation (AF) is the most common sustained cardiac arrhythmia currently; affects approximately 33 million people worldwide ${ }^{1}$ with an estimated prevalence of 1 to $4 \%$ in adults, and may be paroxysmal ${ }^{2}$. Its clinical importance lies in the fact that most patients have little or no specific symptoms of this arrhythmia ${ }^{3}$, besides being associated with several hemodynamic complications and increased morbidity and mortality in patients who has $i t^{2}$. Therefore, its early detection - although difficult most of the time - is useful for monitoring and adequate management of patients in order to avoid secondary complications $\mathrm{s}^{2,4}$.

The diagnosis and monitoring of subclinical AF its asymptomatic form - is preferably performed from electrocardiogram ${ }^{4}$; however, in patients with a cardiac pacemaker, it is possible to diagnose it by the analysis of the recording and storage of data of the device 5 . Pacemakers not only perform their function of identifying and correcting problems in cardiac electrical stimulation but are also able to accurately record abnormal cardiac events, registering the day, time and duration ${ }^{6}$. Studies point to the prevalence rate of subclinical AF around $10 \%$ in patients with cardiac pacemaker ${ }^{6,7}$ and may vary up to $55.3 \%$ for those aged 65 or over ${ }^{5,7}$.

It is known that all patients with a cardiac pacemaker who had AF recorded in their device should have a regular clinical follow-up with a cardiologist for control and monitoring ${ }^{8}$. Treatment under oral anticoagulation is indicated for the absolute majority of AF patients, except in cases where the hemorrhagic risks outweigh the benefits of preventing thromboembolic complications of arrhythmia ${ }^{4,8}$. However, there are few international studies that evaluate the adequate management of patients with $\mathrm{AF}$ with cardiac pacing, and there is no recent Brazilian study that evaluates this scenario in the patients treated by the Sistema Único de Saude (SUS).

Due to the necessity and importance of adequate clinical follow-up of these patients, this study aims to raise the prevalence of atrial arrhythmias and subclinical $\mathrm{AF}$ in patients with cardiac pacemakers, as well as to investigate how many of them undergo regular clinical follow-up with a cardiologist and use anticoagulant medications.

\section{METHODS}

This is an observational study with a quantitative and descriptive approach. 196 patients with a cardiac pacemaker in the period between July 2015 and April 2016 were attended on an outpatient basis. Of these, 60 patients had cardiac arrhythmias recorded by the pacemaker and were invited to participate in the study.

The setting of the study was the Pacemaker Ambulatory of Hospital de Clínicas (HC) of the Universidade Federal do Paraná (UFPR), which is part of the Cardiovascular Surgery Service and is located in the Ambulatory Medical Service (SAM 2) of the hospital. Outpatient care takes place on the first Monday of each month and is assisted by pacemaker technicians representing the different brands of devices used by the service.

To the 60 patients selected, the objectives of the research were explained and presented the Term of Free and Informed Consent, signed by these and the researchers. Then, the researchers applied a structured interview, which contained two sociodemographic questions (sex and age) and two clinical questions about regular follow-up with a cardiologist and use of anticoagulant drugs.

The collected data were recorded and organized in Excel $^{\circledR}$ software table (Microsoft, 2013) and statistical analysis performed by $\mathrm{R}$ (R Core Team, 2015; version 3.2.3) software. Absolute and relative frequencies were obtained from the following data: the presence of arrhythmic event; the presence of subclinical AF; gender; follow-up with a cardiologist; and use of anticoagulants.

For statistical evaluation, the results were submitted to Fischer's exact test, when qualitative and dichotomous variables, and logistic regression test, when there was a need to predict cause-effect relationships between two variables. Mean, median, minimum, maximum, and standard deviation of the variable age were also obtained, also submitted to Studentss t-test for comparison of paired samples. The reference value for the $\mathrm{p}$-value of $5 \%$ was considered as a determinant of the statistical significance of the sample results.

The research was approved by the Ethics and Research Committee of theUFPR HC (CAAE 44183615.7.0000.0096), and the consolidated opinion was issued on May 9, 2015. 


\section{RESULTS}

Arrhythmic events were recorded in 60 (30.6\%) of 196 patients who went through the outpatient clinic in the period analyzed. Of these 60, 25 (41.6\%) had exclusively ventricular arrhythmias, $16(26.6 \%)$ AF associated with ventricular arrhythmias and 19 (31.6\%) had exclusively AF. Therefore, in relation to the 196 patients, 35 (17.8\%) had AF (Table 1).

Among the study participants, 38 (63.3\%) were male and $22(36.6 \%)$ were female. With regard to the disease studied (subclinical AF) and the gender of the participants, it was observed that the chance of subclinical AF in female patients is 3.77 times that of male patients [odds ratio $(\mathrm{OR})=3,77 ; 95 \%$ confidence interval $(95 \% \mathrm{CI}) 1.21-13.42 ; \mathrm{p}=0.0277]$. The mean age of the patients was $68.1 \pm 12.1$ years; however, there were no statistically significant relationships between the age of the patients and the presence or absence of subclinical AF ( $p=0.5876)$.

More than half of the 60 patients studied (53.3\%, $\mathrm{n}=32$ ) had regular follow-up with a cardiologist, and among the 35 patients with subclinical AF, 18 (51.4\%) underwent cardiac monitoring. Of the 25 patients who have exclusively ventricular arrhythmias, 14 (56\%) follow up with a cardiologist and the other $11(44 \%)$ do not (Fig. 1). There was no statistically significant difference between the two groups (subclinical AF and exclusively ventricular arrhythmias) for regular follow-up with cardiologists $(\mathrm{p}=0.7964)$.

Of the 60 patients studied, 14 (23.3\%) used anticoagulants. Of the 35 patients with subclinical AF, $29(82.8 \%)$ did not use drugs of this class (Fig. 2). Taking into account the follow-up with a cardiologist, it was observed that 16 patients with subclinical AF, in addition to not taking anticoagulant drugs, did not proceeded with medical follow up (45.7\%).

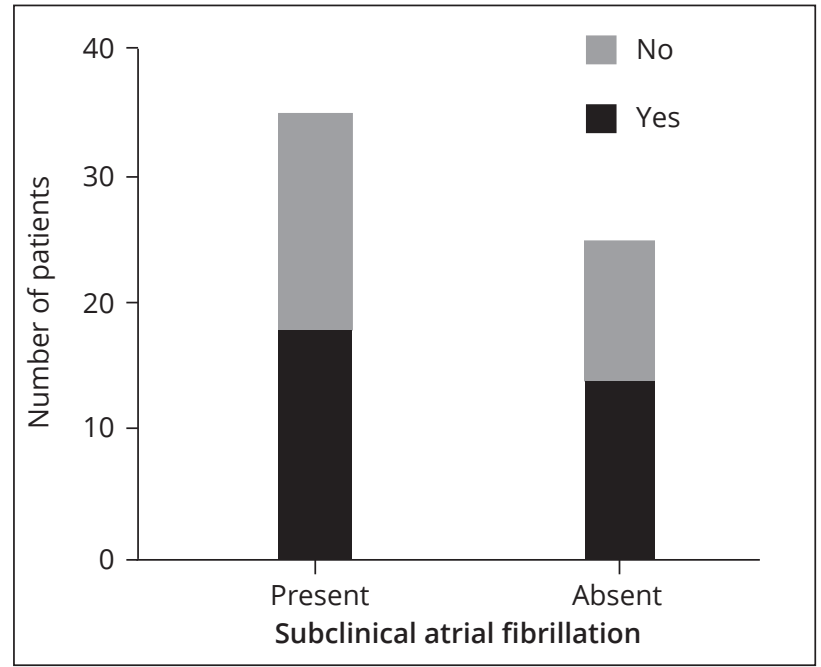

Figure 1. Follow up with a cardiologist.

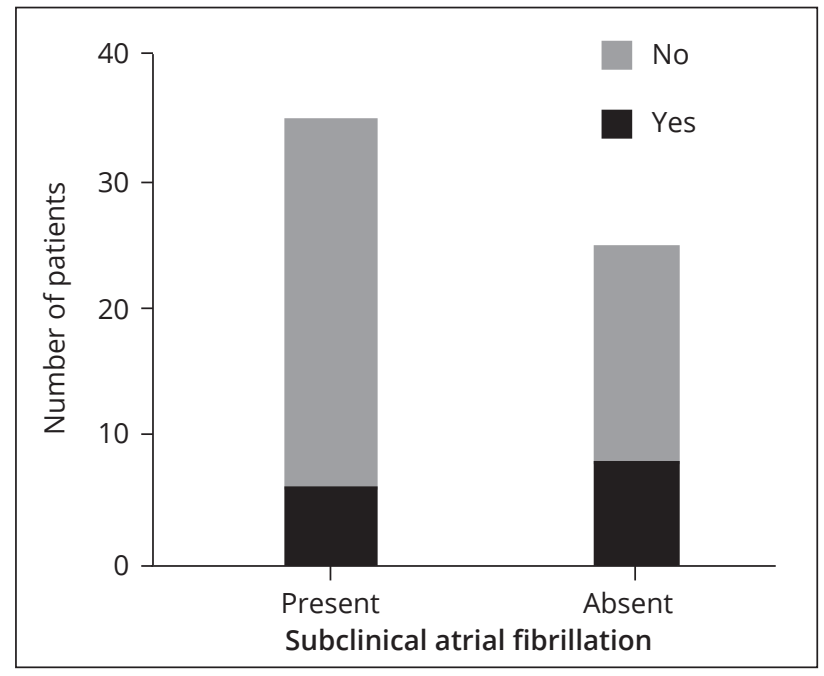

Figure 2. Use of oral anticoagulant drugs.

Table 1. Clinic and sociodemographic characteristics of the study group.

\begin{tabular}{lccc}
\hline \multicolumn{1}{c}{ Patients } & $\begin{array}{c}\text { With cardiac } \\
\text { arrhythmias } \\
(\mathbf{n = 6 0 )}\end{array}$ & $\begin{array}{c}\text { With subclinical } \\
\text { atrial fibrillation } \\
(\mathbf{n}=35)\end{array}$ & $\begin{array}{c}\text { No subclinical } \\
\text { atrial fibrillation } \\
(\mathbf{n}=\mathbf{2 5})\end{array}$ \\
\hline Gender & & & $20(80.0)$ \\
$\quad$ Male [n (\%)] & $38(63.3)$ & $18(51.4)$ & $5(20.0)$ \\
$\quad$ Female [n (\%)] & $22(36.6)$ & $17(48.5)$ & $69.2 \pm 10.6$ \\
Age (mean \pm Standard deviation) & $68 \pm 12.1$ & $67.4 \pm 13.1$ & $25(100.0)$ \\
Ventricular arrhythmias [n (\%)] & $41(68.3)$ & $16(45.7)$ & $14(56.0)$ \\
Cardiological follow-up [n (\%)] & $32(53.3)$ & $18(51.4)$ & $8(32.0)$ \\
Use of oral anticoagulants [n (\%)] & $14(23.3)$ & $6(17.1)$ & \\
\hline
\end{tabular}




\section{DISCUSSION}

The main results of this research highlight the high prevalence $(30.6 \%)$ of occurrence of cardiac arrhythmias in addition to the underlying diseases that indicated implantation of a pacemaker in the patients observed. Cardiac arrhythmias recorded by pacemakers - also called «events» - are broken down in telemetry and can be archived by the technicians and then analyzed by the cardiac surgeon in charge.

$\mathrm{AF}$, in its subclinical form, is responsible for more than half of the arrhythmias in the studied group. It is associated with a 2.5 -fold increased risk of possible hemodynamic complications, such as cerebrovascular accident (stroke) and systemic embolism ${ }^{7}$. The rate of subclinical AF observed in the patients in this study was $17.8 \%$, whereas the literature presents variable rates: some studies ${ }^{6,7}$ rates close to $10 \%$, while others ${ }^{5,9}$ found rates close to $40 \%$. This observed difference may be related to the data collection time. Healey et al. ${ }^{7}$ followed patients for a period of three months and obtained a rate of $10.1 \%$, while Cabrera et al. ${ }^{9}$ followed patients for a period of 5.5 years and obtained a rate of $36.9 \%$. Another important factor that may influence the rate of occurrence of $\mathrm{AF}$ is the criterion of patient selection, since male, Caucasian, smokers, obese patients with a previous history of cardiovascular problems are at greater risk of developing $\mathrm{AF}^{1}$.

In contrast, this research demonstrated a greater chance of AF occurring in female patients, which contrasts with results presented in the literature. Schnabel et al. ${ }^{10}$ risk factors for the development of $\mathrm{AF}$, one being the male gender. However, there are studies that found no significant relationship between gender and the occurrence of $\mathrm{AF}$ in patients with pacemakers ${ }^{11-13}$.

Still in relation to the sociodemographic data analyzed, a predominance of the elderly in the study group (mean age 68 years) was observed, although no significant relationship was found between this aspect and the presence or absence of subclinical AF. It is known that age above 60 years is one of the risk factors for the development of $\mathrm{AF}^{10}$ and other studies were able to relate this information to AF detected by implantable devices $^{5-7,9,14}$.

One variable studied in this study, of great clinical importance, was the regular follow-up of cardiac arrhythmias in a cardiologist doctor. The guidelines point to the need for follow-up and clinical cardiological management for those with cardiac arrhythmias, whether atrial or ventricular arrhythmias ${ }^{15,16}$. The cardiologist is responsible for investigating and choosing the ideal therapy for the control and attenuation of possible arrhythmic symptoms, in order to provide a better quality of life for patients with these conditions, as well as to prevent related complications ${ }^{15,16}$.

The present study found that approximately half of the patients with subclinical AF (48.6\%) do not have a regular cardiological follow-up. A similar relationship was observed in the group of patients who presented ventricular arrhythmias; of these, only 56\% follow up with a cardiologist. Therefore, there was a lack of information on this group about the importance of having a cardiological follow-up, as well as the difficulty of access to cardiologists by the patients in this study.

The vast majority $(82.8 \%)$ of the patients who presented subclinical AF did not use anticoagulant drugs. A similar result is highlighted by Healey et al. ${ }^{5}$, which portray an unfavorable scenario for patients who need to use this type of drug; the authors emphasize that anticoagulants are prescribed for less than a quarter of patients who have asymptomatic $\mathrm{AF}^{5}$. Nevertheless, another study that exclusively evaluates the beginning of anticoagulant treatment in patients with $\mathrm{AF}$ emphasizes that in more than $77 \%$ of the patients observed there would be a need for anticoagulant drug therapy, however, in only $61 \%$ of these it is performed ${ }^{6}$.

It should be noted that a group of patients studied in this research, besides not having regular follow-up with a cardiologist, does not use anticoagulant drugs. This group denoted the rate of $45.7 \%$ among patients with subclinical AF and was considered the most vulnerable to the thromboembolic complications of this asymptomatic disease.

The main limitation of this study is its short period of data collection (10 months) and, consequently, the small sample size used for statistical calculations. Therefore, new research is needed to analyze the variables studied in a larger number of patients, in order to increase the accuracy of the calculated results 


\section{CONCLUSION}

A significant portion of the patients with pacemakers treated ambulatorily in HC-UFPR have AF recorded by the device. However, although primordial, almost half of these patients do not undergo clinical follow-up with a cardiologist and less than one-fifth of patients with AF undergoing anticoagulant therapy. New studies that increase the number of patients studied are necessary to increase the statistical accuracy.

\section{AUTHORS' CONTRIBUTIONS}

\author{
Conceptualization, Mulinari, LA; Methodology,
} Mulinari LA, Brunello LFS and Figueiredo, GA; Research, Mulinari LA, Brunello LFS and Figueiredo, GA; Writing, Mulinari L A, Brunello LFS and Figueiredo GA; First version, Mulinari LA, Brunello LFS and Figueiredo GA; Review, Mulinari LA, Brunello, LFS and Figueiredo, GA; Supervision, Mulinari, LA.

\section{REFERENCES}

1. Ball J, Carrington MJ, McMurray JJV, Stewart S. Atrial fibrillation: profile and burden of an evolving epidemic in the 21st century. Int J Cardiol. 2013;167(5):1807-24. https://doi. org/10.1016/j.ijcard.2012.12.093

2. Rahman F, Kwan GF, Benjamin Ej. Global epidemiology of atrial fibrillation. Nat Rev Cardiol. 2014;11(11):639-54. https://doi.org/10.1038/nrcardio.2014.118

3. Israel CW, Grönefeld G, Ehrlich JR, Li Y-G, Hohnloser $\mathrm{SH}$. Long-term risk of recurrent atrial fibrillation as documented by an implantable monitoring device. J Am Coll Cardiol. 2004;43(1):47-52. https://doi.org/10.1016/j. jacc.2003.08.027

4. Camm AJ, Kirchhof P, Lip GYH, Schotten U, Savelieva I, Ernst $\mathrm{S}$, et al. Guidelines for the management of atrial fibrillation: The Task Force for the Management of Atrial Fibrillation of the European Society of Cardiology (ESC). Eur Heart J. 2010;31(19):2369-429. https://doi.org/10.1093/eurheartj/ ehq278

5. Healey JS, Martin JL, Duncan A, Connolly SJ, Ha AH, Morillo CA, et al. Pacemaker-detected atrial fibrillation in patients with pacemakers: prevalence, predictors, and current use of oral anticoagulation. Can J Cardiol. 2013;29(2):224-8. https:// doi.org/10.1016/j.cjca.2012.08.019

6. Yedlapati N, Fisher JD. Pacemaker diagnostics in atrial fibrillation: limited usefulness for therapy initiation in a pacemaker practice. Pacing Clin Electrophysiol. 2014;37(9):1189-97. https://doi.org/10.1111/pace.12392

7. Healey JS, Connolly SJ, Gold MR, Israel CW, Van Gelder IC, Capucci A, et al. Subclinical atrial fibrillation and the risk of stroke. N Engl J Med. 2012;366(2):120-9. https://doi. org/10.1056/NEJMoa1105575

8. January CT, Wann LS, Alpert JS, Calkins H, Cleveland Jr JC, Cigarroa JE, et al. 2014 AHA/ACC/HRS Guideline for the Management of Patients With Atrial Fibrillation: Executive summary. J Am Coll Cardiol. 2014;(212):1-57. https://doi. org/10.1161/CIR.0000000000000041

9. Cabrera S, Mercé J, Castro R de, Aguirre C, Carmona A, Pinedo M, et al. Pacemaker clinic: An opportunity to detect silent atrial fibrillation and improve antithrombotic treatment. Europace. 2011;13(11):1574-9. https://doi.org/10.1093/ europace/eur160
10. Schnabel RB, Sullivan LM, Levy D, Pencina MJ, Massaro JM, D'Agostino RB, et al. Development of a risk score for atrial fibrillation (Framingham Heart Study): a community-based cohort study. Lancet. 2009;373(9665):739-45. https://doi. org/10.1016/S0140-6736(09)60443-8

11. Mabo P, Victor F, Bazin P, Ahres S, Babuty D, Costa A da, et al. A randomized trial of long-term remote monitoring of pacemaker recipients (The COMPAS trial). Eur Heart J. 2012;33(9):1105-11. https://doi.org/10.1093/eurheartj/ehr419

12. Glotzer TV, Daoud EG, Wyse DG, Singer DE, Ezekowitz MD, Hilker $C$, et al. The relationship between daily atrial tachyarrhythmia burden from implantable device diagnostics and stroke risk the trends study. Circ Arrhythmia Electrophysiol. 2009;2(5):474-80. https://doi.org/10.1161/ CIRCEP.109.849638

13. Defaye P, Leclercq J-F, Guilleman D, Scanu P, Hazard J-R, Fatemi $\mathrm{M}$, et al. Contributions of high resolution electrograms memorized by DDDR pacemakers in the interpretation of arrhythmic events. Pacing Clin Electrophysiol. 2003;26 (1 Pt 2):214-20. https://doi.org/10.1046/j.1460-9592.2003. 00019.x

14. Kaufman ES, Israel CW, Nair GM, Armaganijan L, Divakaramenon S, Mairesse $\mathrm{GH}$, et al. Positive predictive value of device-detected atrial high-rate episodes at different rates and durations: an analysis from ASSERT. Hear Rhythm. 2012;9(8):1241-6. https://doi.org/10.1016/j. hrthm.2012.03.017

15. PrioriSG, Blomström-LundqvistC, MazzantiA, Blom N, Borggrefe M, Camm J, et al. 2015 ESC Guidelines for the management of patients with ventricular arrhythmias and the prevention of sudden cardiac death. Eur Heart J. 2015;36(41):2793-867. https://doi.org/10.1093/eurheartj/ehv316

16. Page RL, Joglar JA, Caldwell MA, Calkins H, Conti JB, Deal BJ, et al. 2015 ACC/AHA/HRS Guideline for the Management of Adult Patients With Supraventricular Tachycardia. Circulation. 2015;64(21). https://doi.org/10.1161/CIR.0000000000000311 